\title{
ANÁLISE DO MÉTODO DE AVALIAÇÃO TÉRMICA DOS PROJETOS DE PRÉ-ESCOLAS DO PROGRAMA PROINFÂNCIA
}

\author{
ANALYSES OF THE THERMAL EVALUATION METHOD OF PROINFÂNCIA PROGRAM \\ PRESCHOOL DESIGNS
}

\author{
Gabriela Sartori ${ }^{1}$ \\ Luiz Carlos Pinto da Silva Filho ${ }^{2}$ \\ Maurício Carvalho Ayres Torres ${ }^{3}$ \\ 'Universidade Federal do Rio Grande do Sul, \\ Porto Alegre, RS, Brasil, \\ gabriela.sartori2@gmail.com \\ 2 Universidade Federal do Rio Grande do Sul, \\ Porto Alegre, RS, Brasil, \\ Icarlos66@gmail.com \\ 3 Universidade Federal do Rio Grande do Sul, \\ Porto Alegre, RS, Brasil, \\ mauricio.torres@ufrgs.br
}

Contribuição dos autores:

GS: conceituação, análise formal,

investigação, metodologia, administração de projetos, validação, visualização, escrita rascunho original, escrita - revisão e edição. LCPSF: conceituação, metodologia,

supervisão. MCAT: conceituação, análise formal, metodologia, administração de projetos, recursos, visualização, escrita revisão e edição.

Fomento: Não houve fomento

Declaração de conflito: nada foi declarado.

Editor Responsável:

Vanessa Gomes da Silva (D)

\begin{abstract}
Resumo
O Programa Proinfância, criado para suprir o déficit de vagas em pré-escolas, apresenta projetos padrão para facilitar processos de licitações e sua implementação nos municípios brasileiros. O Manual de Orientações Técnicas do Programa exige que os projetos cumpram o nível Mínimo de desempenho térmico para inverno e o nível Intermediário para verão, de acordo com o método de simulação da NBR 15.575:2013. Entretanto, o Manual não correlaciona os níveis de desempenho térmico com temperaturas de conforto térmico adequadas ao desenvolvimento das atividades escolares. Dessa maneira, este trabalho analisa a adequação do método de avaliação térmica das pré-escolas proposto pelo Manual, correlacionando os níveis de desempenho térmico alcançados por um projeto padrão com temperaturas de conforto térmico nas 8 zonas bioclimáticas definidas pela NBR 15.220:2005. O desempenho térmico foi avaliado pelo método de simulação da NBR 15.575:2013, enquanto o conforto térmico foi analisado de acordo com o modelo adaptativo da ASHRAE Standard 55-2017. Adaptações ao método de simulação tiveram que ser feitas para a avaliação do desempenho térmico da pré-escola, já que a NBR 15.575 contempla somente edificações residenciais, deixando lacunas a serem preenchidas. Verificou-se que os parâmetros não definidos na Norma de Desempenho e no Manual do programa podem alterar a classificação de desempenho térmico do projeto. Além disso, temperaturas resultantes da avaliação de desempenho térmico extrapolam significantemente os níveis de conforto térmico, ainda que alcançando classificações aceitas pelo Manual do Proinfância. Este estudo ressalta a importância do desenvolvimento de normativa específica de conforto térmico para tipologias escolares.
\end{abstract}

Palavras-chave: Conforto térmico. Desempenho térmico. NBR 15.575. Simulação computacional. Programa Proinfância.

\begin{abstract}
Proinfância Program was created to increase preschools vacancies and introduce standardized designs to facilitate bidding processes and their implementation in Brazilian municipalities. The Program Manual requires that any preschool design achieves the Minimum level of thermal performance for winter and the Intermediate level for summer, according to the simulation method of NBR 15.575: 2013. However, the Manual does not correlate the thermal performance levels with thermal comfort temperatures for the appropriate development of scholar activities. Thus, this work analyzes the adequacy of the thermal assessment method of preschools proposed by the Manual by correlating the thermal performance levels achieved by a standard design with thermal comfort temperature ranges in the eight bioclimatic zones defined by NBR 15.220: 2005. Thermal performance was assessed using the NBR 15,575: 2013 simulation method, while thermal comfort was analyzed according to the ASHRAE Standard 55-2017 adaptive model. In order to reduce uncertainties of the NBR 15,575 simulation method because of its residential focus, adaptations were made to assess the preschool thermal performance. It was found that the undefined parameters of the NBR and the Proinfância Manual might change the project's thermal performance classification. Furthermore, the thermal performance assessment temperatures are not following thermal comfort ranges, nevertheless reaching allowable classifications by the Proinfância Manual. This study emphasizes the importance of developing specific thermal comfort regulations for schools..
\end{abstract}

Keywords: Thermal comfort. Thermal performance. NBR 15.575. Computer simulation. Proinfância Program.

How to cite this article:

SARTORI, G.; SILVA FILHO, L. C. P. da .; TORRES, M. C. A. Análise do método de avaliação térmica dos projetos de préescolas do programa Proinfância.. PARC Pesquisa em Arquitetura e Construção, Campinas, SP, v. 12, p. e021020, 2021. DOI: http://dx.doi.org/10.20396/parc.v12i00.8661249 


\section{Introdução}

Para corrigir o déficit de vagas e garantir o acesso de crianças de o a 6 anos em creches e pré-escolas públicas, em 2007, o Governo Federal instituiu o Programa Proinfância. O programa foi criado com o objetivo de melhorar a infraestrutura escolar infantil brasileira com a construção de edificações escolares e aquisição de equipamentos e mobiliário. A construção de creches e pré-escolas, por meio de assistência técnica e financeira do Fundo Nacional de Desenvolvimento da Educação (FNDE), pode ser através de projetos padronizados fornecidos pelo FNDE ou através de projetos próprios elaborados pelos proponentes. Os projetos padrão foram desenvolvidos com a intenção de facilitar o processo de assistência financeira aos municípios. Primeiramente, os projetos padrão eram do Tipo B e C, sendo substituídos em 2014 pelos projetos do tipo 1 e 2. De acordo com dados fornecidos pelo FNDE, mais de 5.600 pré-escolas de todas as tipologias já haviam sido construídas ou estavam em fase de construção desde o início do programa (2007) até o ano de 2017 em todo o Brasil e já haviam sido investidos mais de 5 bilhões de reais (BRASIL, 2018).

Kowaltowski (2011) aponta que diversas instituições públicas como escolas, hospitais e creches, com o objetivo de atender a programas de necessidades e atividades estabelecidas pelos órgãos responsáveis, frequentemente adotam um projeto padrão. Rheingantz et al. (2017) alegam que ao invés de priorizar as crianças, as práticas pedagógicas e as relações produzidas no ambiente escolar, o Programa prioriza as políticas públicas para licitação e construção de pré-escolas, respondendo às metas e objetivos do Proinfância com projetos padrão que desprezam as diferenças contextuais e os valores culturais das comunidades.

\section{Avaliação térmica das pré-escolas do Programa Proinfância}

Em 2017, o FNDE disponibilizou uma nova versão do Manual de Orientações Técnicas para elaboração de projetos de edificações escolares (volume II) (BRASIL, 2017), contendo diretrizes para a avaliação do desempenho térmico dos projetos padrão do Programa Proinfância. O manual exige desempenho térmico Intermediário (I) para as condições de verão e Mínimo (M) para as condições de inverno, de acordo com os critérios de avaliação pelo método de simulação de desempenho térmico da NBR 15.5751 (ABNT, 2013). Apesar das exigências em relação ao desempenho térmico da edificação, o Manual do Proinfância não comenta sobre níveis de conforto térmico adequados para o desenvolvimento das atividades escolares. Em uma tipologia que atende função tão nobre como a educação infantil, é importante que se atinja um nível adequado de conforto térmico para que as atividades escolares possam ser desenvolvidas de maneira saudável. Pesquisas referentes a conforto no ambiente pré-escolar do Programa Proinfância (PEGLOW et al., 2016; BABICK; TORRES, 2017; MODLER et al., 2018) apresentam níveis inadequados de conforto térmico e demonstram a inadequação do uso de projetos padrão em um país de grande extensão territorial e oito zonas bioclimáticas distintas como o Brasil de acordo com as definições da NBR 15.220-3 Desempenho Térmico de Edificações (ABNT, 2005b).

Nota-se que o método de simulação da NBR 15.575, que é o indicado pelo Manual do Programa Proinfância, não é utilizado nos estudos para a avaliação térmica dos projetos padrão. Dos autores revisados, apenas Babick e Torres (2017) utilizaram a NBR para comparar as exigências de Transmitância e Capacidade térmica para paredes e cobertura da norma com as características do projeto padrão Tipo C, não utilizando, portanto, o método de simulação. A NBR 15.575 foi desenvolvida para a avaliação de edificações habitacionais. Assim, para a avaliação de uma tipologia diferente da habitacional, como um prédio público escolar, a norma não contempla alguns 
parâmetros necessários à realização da avaliação térmica. Através de revisão bibliográfica, podemos afirmar que o procedimento de simulação vigente na NBR 15.575-1 também não considera alguns parâmetros importantes que influenciam no desempenho térmico das edificações residenciais, como cargas térmicas internas, condições de contato com o solo e ventilação natural não correspondendo com a realidade de ocupação e de uso da edificação real.

Silva et al. (2014) investigam a incerteza do uso de valores subjetivos adotados para variáveis desconsideradas pelo método de simulação da NBR 15.575-1, como a data do dia típico de verão e inverno, a velocidade e a direção do vento, o algoritmo de cálculo da irradiação solar e o tipo de céu. Os resultados dos níveis de classificação de desempenho térmico de uma habitação de interesse social variaram devido aos diferentes valores adotados para as variáveis desconsideradas pela NBR 15.575-1. Outra constatação do estudo foi que os modelos que apresentaram os piores níveis de desempenho térmico, tanto no verão quanto no inverno, foram aqueles cujo piso não tinha contato com o solo (piso adiabático). O tipo de céu foi a variável que apresentou maior influência para a análise no verão e inverno para todos os modelos simulados.

Na pesquisa desenvolvida por Sorgato et al. (2014), os resultados do procedimento de simulação da NBR 15.575-1 mostraram que as condições do piso da edificação em contato com o solo impactam significativamente no desempenho térmico. Constatouse que as simulações da edificação com o piso adiabático não atenderam ao critério de desempenho térmico mínimo da NBR 15.575-1.

Soares e Silva (2016) investigaram incoerências entre o método de simulação e o método simplificado da NBR 15.575-1. Concluíram, na análise feita através de simulações utilizando os dias típicos, que não há compatibilidade entre os métodos simplificado e por simulação, pois um grande número de casos analisados por simulação conseguiu alcançar o desempenho térmico mínimo exigido, utilizando valores de propriedades de envoltória muito além do que os especificados no método simplificado. Os mesmos autores propuseram uma revisão dos valores limites das propriedades térmicas do método simplificado, assim como uma metodologia para estabelecer a coerência entre os dois métodos de avaliação de desempenho térmico da NBR 15.575-1.

A investigação sobre a amplitude da classificação dos níveis de desempenho térmico causada pela variação dos valores adotados das variáveis desconsideradas pela NBR 15.575-1 demonstra que o método atual permite que os avaliadores tenham liberdade de escolher quaisquer valores para essas variáveis para obter melhor classificação do nível de desempenho térmico (SILVA et al. 2014). Quando uma variável não é considerada para avaliação, esta não poderia influenciar no resultado do nível de desempenho. Além disso, para que todos os casos sejam avaliados com o mesmo critério, a norma deveria estipular a condição do piso da edificação a ser adotada na simulação, pois dependendo dessa condição, a edificação pode ser aprovada ou reprovada (SORGATO et al. 2014).

Com o intuito de qualificar o ambiente pré-escolar, o presente estudo tem como objetivo analisar e estabelecer uma discussão sobre a adequação do método de avaliação térmica do Manual de Orientações Técnicas do Programa Proinfância aplicado a um dos projetos padrão sugerido, correlacionando os resultados de desempenho térmico obtidos através do método de simulação da NBR 15.575-1:2013 com níveis de conforto térmico alcançados através da aplicação do modelo adaptativo da ASHRAE Standard 55-2017, nas oito zonas bioclimáticas brasileiras. 


\section{Método}

O projeto padrão Tipo 2 (Proj2) do Programa Proinfância foi escolhido como objeto de estudo da pesquisa por ter tido ampla implantação em todo o país. De acordo com dados do FNDE, desde 2014 até 2017, mais de 600 pré-escolas Tipo 2 já haviam sido construídas ou estavam em fase de construção em 25 estados do Brasil (BRASIL, 2018).

Todos os materiais e sistemas componentes deste projeto foram identificados e caracterizados, sendo atribuídos a um modelo térmico tridimensional modelado em um software de simulação computacional. O modelo foi simulado e analisado em relação ao conforto térmico dos usuários e ao desempenho térmico da edificação, de acordo com o método adaptativo da ASHRAE Standard 55-2017 e com o método de simulação da NBR 15.575-1:2013, respectivamente, nas 8 zonas bioclimáticas brasileiras. Para a modelagem do projeto foi utilizado o software SketchUp 2017 com as ferramentas do plugin OpenStudio 2.5.0. As simulações foram executadas no software EnergyPlus 8.8.0. O método de simulação foi escolhido devido ao grande número de variáveis analisadas, à extensão territorial do Brasil, além de ser indicado pelo Manual do Proinfância. Foi escolhido um software de reputação reconhecida e validado por normativas nacionais e internacionais. Também foram utilizados arquivos climáticos confiáveis que podem levar a resultados precisos e indicativos de comportamento térmico.

\section{Modelagem e caracterização construtiva do Projeto Padrão Tipo 2}

A modelagem do Proj2 foi feita com base nas informações do projeto arquitetônico disponíveis no site do FNDE (BRASIL, 2017) (Figura 1), resultando em 24 zonas térmicas.

Figura 1 - Fachada frontal (acima) e lateral (abaixo) do projeto padrão Tipo 2

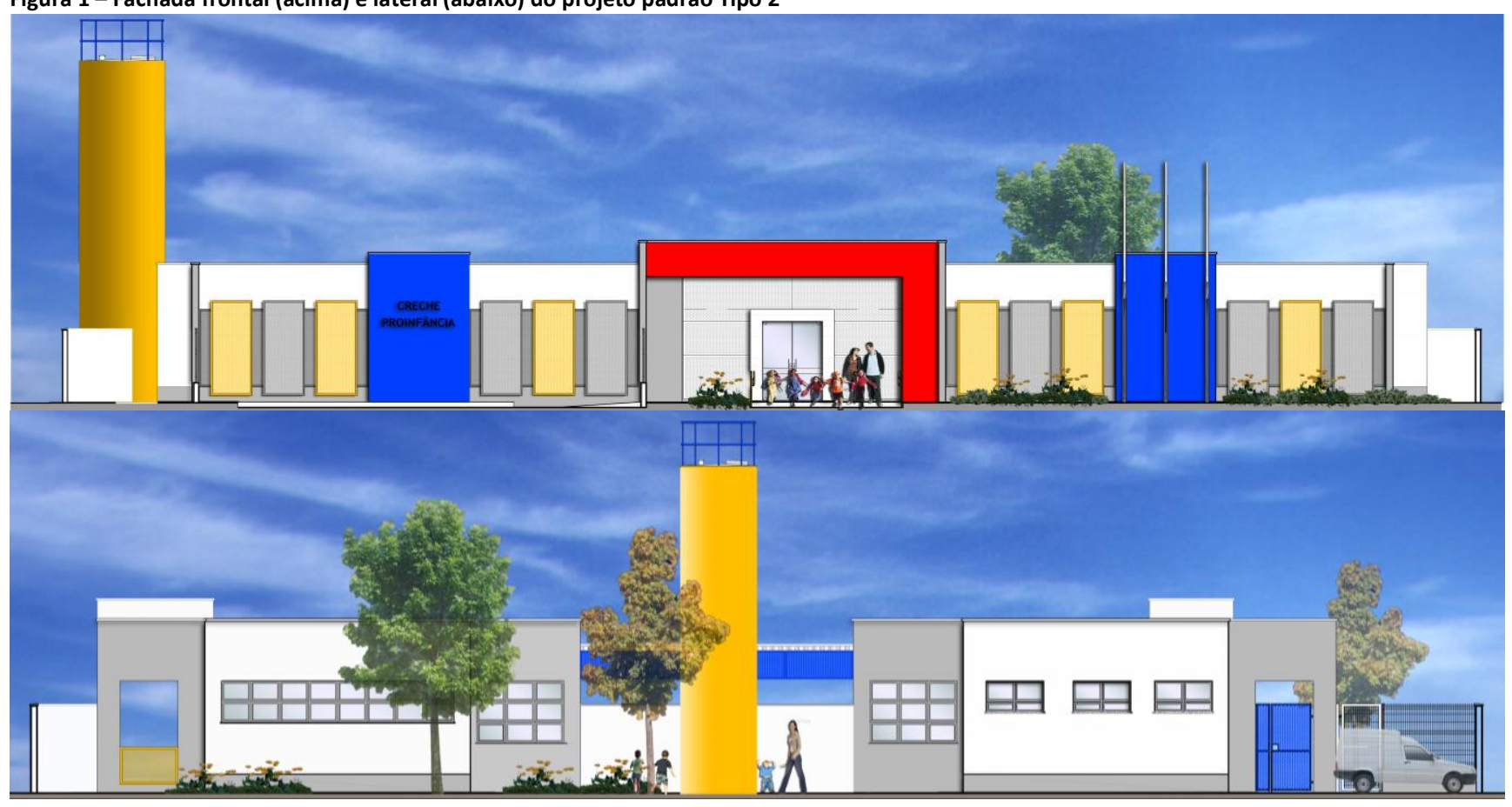

Fonte: FNDE.

Os materiais que compõem a envoltória do Proj2 são organizados e descritos em 5 sistemas: paredes de vedação, cobertura, pisos, estrutura e esquadrias (Quadro 1). 0 projeto possui também elementos de vedação permeáveis, constituídas de chapas de aço perfuradas no solário e na área de serviços, permitindo ventilação natural e sombreamento. Estas chapas possuem pintura esmaltada nas cores amarelo e cinza. 
SARTORI, G.; SILVA FILHO, L. C. P. da .; TORRES, M. C. A

Análise do método de avaliação térmica dos projetos de pré-escolas do programa Proinfância

\begin{tabular}{|c|c|}
\hline Sistema & Composição \\
\hline Paredes de Vedação & $\begin{array}{l}\text { Alvenaria de blocos cerâmicos; } \\
\text { Externas: } 14 \mathrm{~cm} \times 19 \mathrm{~cm} \times 39 \mathrm{~cm} \text {, espessura total de } 20 \mathrm{~cm} ; \\
\text { Internas: } 9 \mathrm{~cm} \times 19 \mathrm{~cm} \times 39 \mathrm{~cm} \text {, espessura total de } 15 \mathrm{~cm} ; \\
\text { Revestimento: argamassa e pintura acrílica na cor branca, interna e externamente, e vermelho } \\
\text { e azul nos pórticos de entrada. }\end{array}$ \\
\hline Cobertura & $\begin{array}{l}\text { Telhas metálicas termoacústicas, e treliças e caibros de aço tipo light steel frame. } \\
\text { Obs.: o projeto não possui laje de cobertura entre os ambientes internos e o telhado, apenas } \\
\text { forro de gesso. }\end{array}$ \\
\hline Pisos & $\begin{array}{l}\text { Ambientes internos: cimentado desempenado, vinílico e cerâmico; } \\
\text { Ambientes externos: concreto desempenado e bloco intertravado de concreto. }\end{array}$ \\
\hline Estrutura & $\begin{array}{l}\text { Vigas e pilares em concreto armado moldado in loco. Viga: } \mathrm{h}=40 \mathrm{~cm} \text {; pilares: } 12 \mathrm{~cm} \times 30 \mathrm{~cm} \text {, } \\
\qquad 12 \mathrm{~cm} \times 40 \mathrm{~cm} \text { ou } 12 \mathrm{~cm} \times 50 \mathrm{~cm} .\end{array}$ \\
\hline Esquadrias & $\begin{array}{l}\text { Janelas: molduras em alumínio na cor natural; vidros temperados e com espessura mínima de } \\
\qquad 6 \mathrm{~mm} ; \\
\text { Portas: Madeira semiocas e com espessura de } 35 \mathrm{~mm} \text {; vidros temperados e com espessura } \\
\text { mínima de } 8 \mathrm{~mm}\end{array}$ \\
\hline
\end{tabular}

Os valores de propriedades como condutividade, densidade de massa aparente e calor específico entre outras características dos materiais de paredes, cobertura, pisos e portas utilizados para o cálculo foram extraídos da NBR 15.220-2 (ABNT, 2005a) (Tabela 1). Como esta NBR não possui dados para as propriedades da Espuma Rígida de Poliisocianurato (PIR) e do piso vinílico, estas foram retirados de catálogos comerciais de fabricantes nacionais.

\begin{tabular}{|c|c|c|c|c|}
\hline Materiais & Espessura (m) & $\begin{array}{c}\text { Condutividade } \\
\text { térmica }(W / m-K)\end{array}$ & $\begin{array}{l}\text { Densidade } \\
\left(\mathrm{kg} / \mathrm{m}^{3}\right)\end{array}$ & $\begin{array}{c}\text { Calor específico } \\
(\mathrm{J} / \mathrm{kg}-\mathrm{K})\end{array}$ \\
\hline Cerâmica (bloco 9x19×39) & 0,019 & 0,9 & 1.600 & 920 \\
\hline Cerâmica (bloco 14×19×39) & 0,0249 & 0,9 & 1.600 & 920 \\
\hline Argamassa interna & 0,03 & 1,15 & 2.000 & 1.000 \\
\hline Argamassa externa & 0,03 & 1,15 & 2.000 & 1.000 \\
\hline Gesso & 0,016 & 0,35 & 900 & 870 \\
\hline Aço & 0,005 & 55 & 7.800 & 460 \\
\hline $\begin{array}{c}\text { Espuma rígida de } \\
\text { Poliisocianurato (PIR) }\end{array}$ & 0,03 & 0,02 & 40 & 1.400 \\
\hline Piso cerâmico & 0,0075 & 1,05 & 2.000 & 920 \\
\hline Piso vinílico & 0,002 & 0,2 & 1.300 & 460 \\
\hline Concreto (contrapiso) & 0,1 & 1,75 & 2.200 & 1.000 \\
\hline Terra argilosa seca & 0,5 & 0,52 & 1.700 & 840 \\
\hline Madeira & 0,035 & 0,15 & 500 & 230 \\
\hline
\end{tabular}

Fonte: os autores.

O coeficiente de absortância de radiação solar da superfície da cobertura e das paredes externas foi considerado 0,2 devido à especificação de acabamento branco para a telha metálica de aço galvanizado e pintura na cor branca para as paredes (ABNT NBR 15.2202, 2005a).

Os valores de transmitância e capacidade térmica de paredes internas, externas e cobertura foram calculados de acordo com a metodologia proposta pela NBR 15.220-2 (ABNT, 2005a). Os valores de transmitância e capacidade térmica encontrados para as paredes foram utilizados para definir a espessura das paredes, de acordo com a metodologia de cálculo da espessura da parede equivalente (ORDENES et al., 2003). 


\section{Métodos de avaliação de desempenho térmico}

A análise do desempenho térmico do objeto de estudo utilizou o método de simulação computacional definido pela NBR 15.575-1 (ABNT, 2013). Esta norma propõe a classificação dos níveis de desempenho térmico em Mínimo (M), Intermediário (I) e Superior (S). Os resultados obtidos foram comparados aos níveis de desempenho térmico exigidos para inverno e verão pelo Manual de orientações técnicas para elaboração de projetos de edificações escolares (BRASIL, 2017), para as tipologias do Programa Proinfância (Intermediário (I) para as condições de verão e Mínimo (M) para as condições de inverno).

O método de simulação da NBR 15.575-1 apresenta algumas incertezas devido a alguns parâmetros que não estão claros ou que não são contemplados na NBR. Além disso, como a NBR 15.575 é uma normativa desenvolvida para edificações habitacionais, o método de avaliação de desempenho térmico pede definições diferentes quando é utilizado para a avaliação de outra tipologia. O Manual do Proinfância também não deixa claro os parâmetros para a aplicação do Método de simulação da NBR para as préescolas. Desta forma, o desempenho térmico da pré-escola foi avaliado de duas maneiras diferentes:

- Simulações de acordo com o Método de simulação da NBR 15.575-1;

- Simulações com adaptações ao Método de simulação da NBR 15.575-1, contendo decisões autônomas para parâmetros não estabelecidos na NBR 15.575-1 e não definidos pelo Manual do Proinfância.

Os parâmetros utilizados nas simulações e as adaptações adotadas estão detalhados no tópico "Parâmetros adotados nas simulações".

Métodos de avaliação do conforto térmico

O Programa Proinfância não contempla financiamento para a aquisição de aparelhos de ar condicionado para as dependências das escolas, sendo que a instalação de sistema de climatização artificial poderia não ser viável para muitos dos municípios brasileiros, tanto pelos custos de aquisição e instalação dos equipamentos, quanto pelos custos de manutenção e de consumo energético. Dessa maneira, o Modelo Adaptativo da Standard 55 (ASHRAE, 2017) foi escolhido para a avaliação do conforto térmico dos usuários, por avaliar ambientes naturalmente ventilados onde são considerados os ajustes comportamentais, fisiológicos e psicológicos dos usuários. Através da aplicação das equações do método adaptativo é possível estabelecer uma faixa com limites mínimos e máximos de temperaturas operativas de conforto para cada mês. Considerou-se uma faixa de temperaturas de conforto para $80 \%$ dos usuários satisfeitos. As temperaturas dos ambientes analisados encontradas nas simulações ao longo do ano letivo foram comparadas com a faixa de temperaturas operativas de conforto calculadas, obtendo-se o Percentual de horas Ocupadas em Conforto (POC).

\section{Parâmetros adotados nas simulações}

Alguns parâmetros contêm explicações sobre as adaptações feitas devido às lacunas deixadas pelo Manual ao escolher uma normativa de habitações para a avaliação térmica de pré-escolas. A avaliação do desempenho térmico resulta em 16 simulações 8 com os parâmetros do método da NBR 15.575 e outras 8 com adaptações ao método dessa norma. Por outro lado, a avaliação de conforto térmico tem 8 simulações de acordo com os parâmetros do modelo adaptativo (Figura 2). Os parâmetros estão detalhados abaixo. 


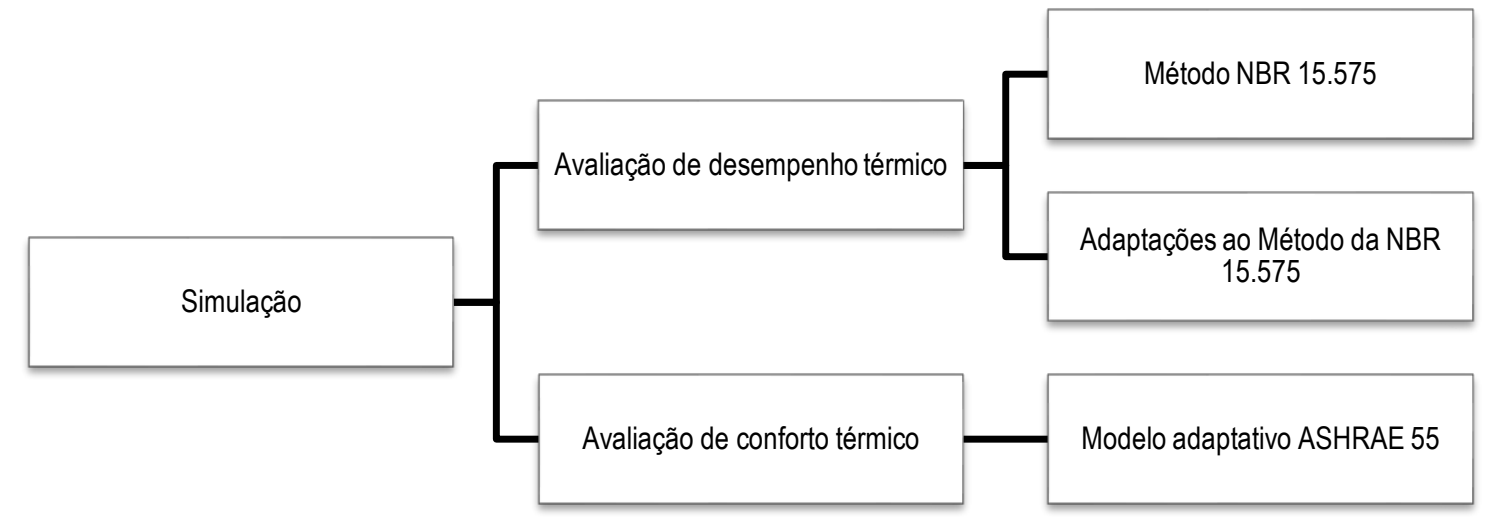

Fonte: os autores.

\section{Ambientes analisados}

A NBR 15.575 (ABNT, 2013) requer somente a avaliação dos ambientes de permanência prolongada, ou seja, salas e quartos. Analogamente, os ambientes de permanência prolongada do Proj2 são: Creches 1 (o a 18 meses), Creche 2 ( 18 meses a 3 anos), Creche 3 ( 3 a 4 anos) e Pré-escola 1 e 2 ( 4 a 6 anos), além da sala de administração (Figura 3). A NBR também aponta que o pior desempenho encontrado para qualquer um dos ambientes de permanência prolongada seja o definidor do desempenho térmico da edificação. Estas mesmas zonas térmicas foram analisadas em relação ao conforto térmico pelo Modelo Adaptativo da Standard 55 (ASHRAE, 2017).

Figura 3 - Ambientes de permanência prolongada e demais ambientes da pré-escola

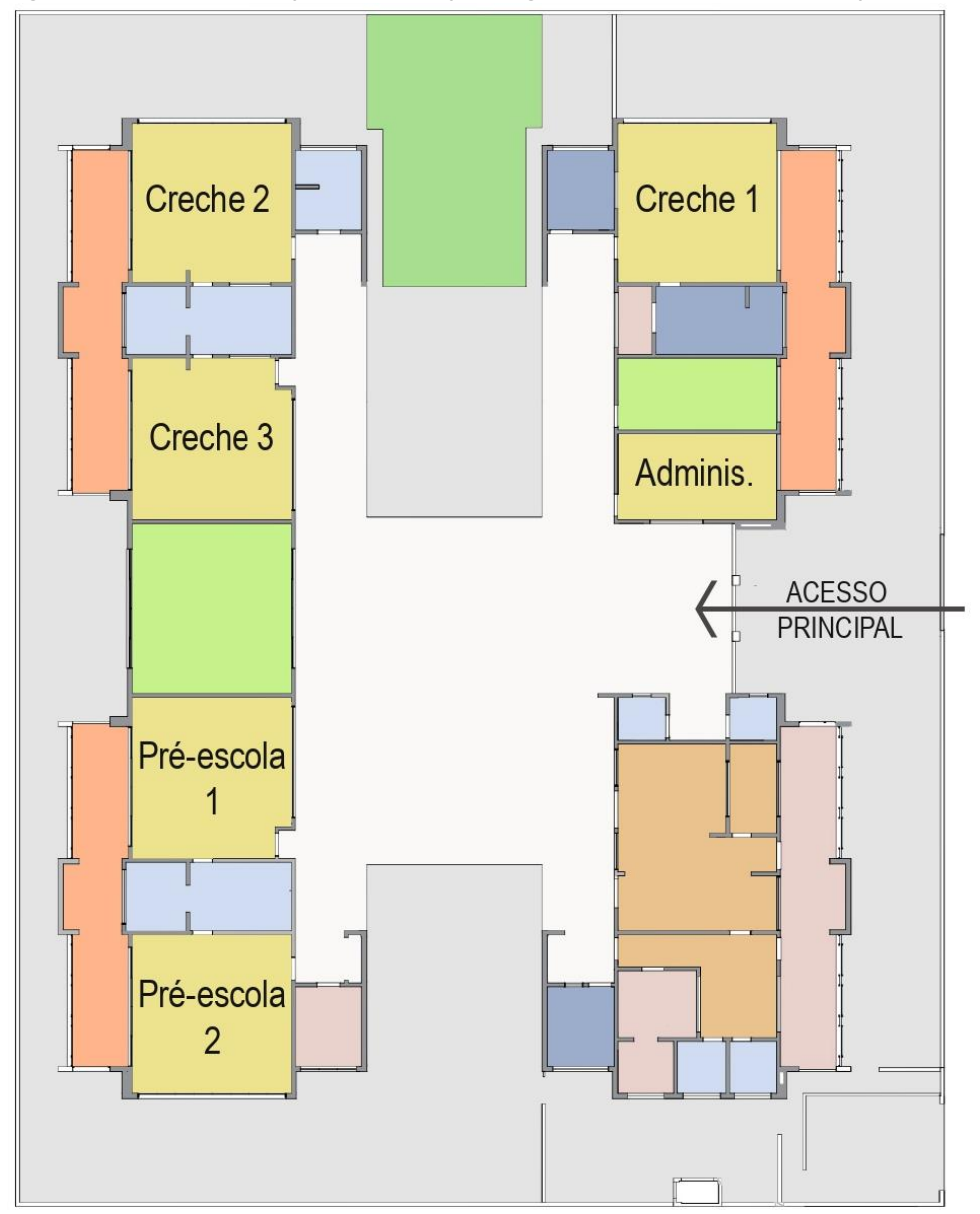

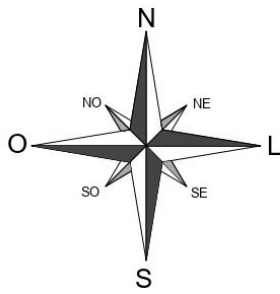

Playground

Salas dos professores/multiuso

Ambientes de permanência prolongada

Cozinha/copa

Solários

Serviços

Sanitários

Amamentação/lactário/fraldário

Pátio coberto/refeitório

Área externa circundante 


\section{Arquivo climático}

$\mathrm{Na}$ avaliação de desempenho térmico foram utilizados os dias típicos de projeto para verão e inverno definidos pela NBR 15.575-1 (ABNT, 2013). Os dados extraídos das tabelas da norma foram as temperaturas máximas e mínimas, a amplitude diária de temperatura e a temperatura de bulbo úmido dos dias típicos. Por outro lado, na avaliação do conforto térmico foi utilizado um arquivo climático anual de referência. Foi escolhida uma cidade representativa de cada zona bioclimática (ZB) pelo critério de maior representatividade populacional em cada zona, com a exceção da ZB 2, para a qual foi escolhida a segunda cidade de maior população por possuir arquivo climático disponível, e a ZB 3, onde a cidade representativa escolhida foi Porto Alegre. Assim, as cidades selecionadas para representaram suas zonas bioclimáticas foram $Z B$ 1 - Curitiba; ZB 2 - Pelotas; ZB 3 - Porto Alegre; ZB 4 - Brasília; ZB 5 - Santos; ZB 6 - Goiânia; ZB 7 Teresina e ZB 8 - Rio de Janeiro.

Horário de funcionamento e temperaturas de referência

O método de simulação da NBR 15.575 considera como referências as temperaturas máximas e mínimas verificadas no ambiente externo e no interior dos ambientes de permanência prolongada, para fins de comparação. Dessa maneira, se a temperatura externa mínima acontecesse às $5 \mathrm{~h}$ da madrugada, ela deveria ser adotada como referência, mesmo não havendo ocupação alguma no edifício escolar. O Manual do FNDE não faz menção a possíveis adaptações a esse método da norma. Dessa maneira, optou-se por considerar somente as temperaturas obtidas nos períodos e horários de efetiva ocupação da edificação, tanto no modelo adaptado de desempenho térmico como nas simulações de conforto térmico. O período de ocupação considerado foi baseado no horário de funcionamento da pré-escola, que acontece de segunda à sextafeira, das $7 \mathrm{~h}$ às $18 \mathrm{~h}$, entre 01 de fevereiro e 21 de dezembro, com exceção dos feriados. O período noturno, assim como todo o mês de janeiro e o período de recesso de Natal não foram considerados como período de ocupação.

Para validar esta decisão de alteração do método da norma de desempenho, também foram executadas simulações de desempenho considerando as temperaturas de referência para qualquer horário, conforme método indicado pela NBR 15.575 (ABNT, 2013).

\section{Trocas térmicas com o solo}

A NBR 15.575 (ABNT, 2013) não comenta sobre a adoção de trocas térmicas da edificação com o solo. Entretanto, estudos (SILVA et al., 2014; SORGATO et al., 2014; SOARES; SILVA, 2016) comprovam que a não utilização deste parâmetro impacta de maneira contundente nas temperaturas resultantes internas, ainda mais quando se trata de edificações térreas, em total contato com o solo, como no caso do Proj2. Assim, foram executadas simulações de desempenho térmico com e sem a consideração das trocas térmicas do piso com o solo para analisar a influência deste parâmetro nos resultados. Nas simulações de desempenho sem as trocas térmicas, o piso foi considerado com uma superfície adiabática. Para as simulações que levam em conta as trocas térmicas, as temperaturas do solo ao longo do ano foram calculadas com auxílio da ferramenta Slab, disponível no EnergyPlus. Os resultados obtidos através desta ferramenta foram inseridos no programa de simulação para a modelagem das temperaturas dinâmicas do solo ao longo do ano.

Nas simulações de conforto térmico, as trocas térmicas entre piso e solo foram consideradas. 


\section{Cargas térmicas de ocupação, iluminação e equipamentos}

O edifício escolar atende até 188 crianças com idades entre zero e seis anos, além de professores e funcionários. A Standard 55 (ASHRAE, 2017) apresenta taxas metabólicas para atividades típicas de escritório para adultos. Porém, de acordo com a mesma referência, as taxas metabólicas podem ser aplicadas a grupo de crianças em ambientes escolares. Dessa maneira, a taxa metabólica considerada para as crianças foi de 1,0 met ou $60 \mathrm{~W} / \mathrm{m}^{2}$ e para os professores e funcionários de 1,2 met ou $70 \mathrm{~W} / \mathrm{m}^{2}$. O número de ocupantes para cada um dos ambientes de permanência prolongada é apresentado na Tabela 2 abaixo.

As cargas térmicas de iluminação e de equipamentos elétricos para as salas de permanência prolongada foram estabelecidas de acordo com o projeto de instalações elétricas disponibilizado pelo FNDE (BRASIL, 2013) e estão organizados na Tabela 2.

$\mathrm{Na}$ avaliação de desempenho térmico, o método de simulação computacional da NBR 15.575 (ABNT, 2013) especifica que as simulações sejam feitas sem levar em conta as cargas térmicas internas decorrentes da ocupação, da iluminação e de equipamentos. Entretanto, em ambientes escolares, onde haverá a concentração de várias pessoas e equipamentos, a carga térmica poderá ser elevada. Assim, foram executadas simulações de desempenho térmico com e sem cargas térmicas para analisar seus impactos nos resultados. Nas simulações de conforto térmico, as cargas térmicas internas são levadas em consideração.

Tabela 2 - Número de ocupantes e carga térmica por ambiente

\begin{tabular}{ccccc} 
Ambiente & $\begin{array}{c}\text { No de } \\
\text { alunos }\end{array}$ & $\begin{array}{c}\text { No de professores/ } \\
\text { funcionários }\end{array}$ & $\begin{array}{c}\text { Iluminação } \\
\text { (W) }\end{array}$ & Equipamentos (W) \\
\hline Administração & - & 2 & 128 & - \\
\hline Creche 1 & 10 & 1 & 256 & 150 \\
\hline Creche 2 & 16 & 1 & 256 & 150 \\
\hline Creche 3 & 20 & 1 & 256 & 150 \\
\hline Pré-escola 1 & 24 & 1 & 384 & 150 \\
\hline Pré-escola 2 & 24 & 1 & 384 & 150 \\
\hline
\end{tabular}

Fonte: os autores.

\section{Infiltração e ventilação natural}

A NBR 15.575-1 estipula, inicialmente, o valor constante de 1 renovação de ar por hora nos ambientes internos a fim de simular uma taxa de infiltração de ar quando as aberturas estão fechadas. Esta condição foi adotada para a análise de desempenho térmico da edificação. A norma ainda permite utilizar uma ventilação de 5 renovações de ar por hora no caso de não atendimento aos valores mínimos de desempenho térmico para verão.

O Modelo Adaptativo da Standard 55 (ASHRAE, 2017) considera a ventilação natural dos ambientes internos da edificação em análise. Para a avaliação do conforto térmico, a ferramenta AirflowNetwork do EnergyPlus foi utilizada para simular essa ventilação natural, levando em conta a diferença de temperatura entre o ar interno e externo à edificação, a diferença de altura entre entradas e saídas de ar, a convecção do calor ascendente e a velocidade e direção do vento (constante no arquivo climático). O modo de controle das aberturas adotado foi o ASHRAE55Adaptive do EnergyPlus, que analisa as temperaturas resultantes nos ambientes internos, verificando quando o nível de conforto térmico é alcançado, determinando a abertura e o fechamento das janelas para manter o nível de conforto térmico. Dessa maneira, também foi configurado o fator de abertura das janelas e o coeficiente do fluxo de massa de ar quando as aberturas estão fechadas. 


\section{Comparativo entre parâmetros de desempenho e conforto térmico}

Os parâmetros adotados não são os mesmos para as avaliações de conforto e desempenho térmico. Além disso, optou-se por avaliar o desempenho térmico com simulações de configurações distintas para desenvolver uma análise sobre o método de avaliação térmica dos projetos padrão do Proinfância. Para facilitar a compreensão de quais parâmetros foram utilizados para cada avaliação (desempenho térmico - com e sem adaptações - e conforto térmico), o Quadro 2 faz a comparação entre os parâmetros adotados em cada uma.

Quadro 2 - Parâmetros de simulação adotados para cada uma das análises

\begin{tabular}{|c|c|c|c|}
\hline Parâmetros & $\begin{array}{l}\text { Desempenho térmico } \\
\text { ABNT NBR 15.575:2013 }\end{array}$ & $\begin{array}{c}\text { Desempenho térmico } \\
\text { Adaptações à NBR } \\
\text { 15.575:2013 }\end{array}$ & $\begin{array}{c}\text { Conforto térmico } \\
\text { Modelo Adaptativo } \\
\text { ASHRAE Standard 55-2017 }\end{array}$ \\
\hline Ambientes analisados & $\begin{array}{c}\text { Ambientes de } \\
\text { permanência prolongada }\end{array}$ & $\begin{array}{c}\text { Ambientes de } \\
\text { permanência prolongada }\end{array}$ & $\begin{array}{c}\text { Ambientes de permanência } \\
\text { prolongada }\end{array}$ \\
\hline Orientação solar & Acesso principal - Leste & Acesso principal - Leste & Acesso principal - Leste \\
\hline Arquivo climático & $\begin{array}{l}\text { Dias típicos } \\
\text { (verão e inverno) }\end{array}$ & $\begin{array}{l}\text { Dias típicos } \\
\text { (verão e inverno) }\end{array}$ & Ano de referência \\
\hline $\begin{array}{l}\text { Horário de funcionamento e } \\
\text { temperaturas de referência }\end{array}$ & $\begin{array}{l}\text { Ano inteiro } \\
24 \text { horas }\end{array}$ & $\begin{array}{l}\text { Calendário escolar } \\
\text { Horário de ocupação }\end{array}$ & $\begin{array}{l}\text { Calendário escolar } \\
\text { Horário de ocupação }\end{array}$ \\
\hline Trocas térmicas com o solo & Não & Sim & Sim \\
\hline $\begin{array}{c}\text { Cargas térmicas de } \\
\text { ocupação/iluminação/equipamentos }\end{array}$ & Não & Sim & Sim \\
\hline Infiltração/Ventilação natural & 1 Renovação de ar/hora & 1 Renovação de ar/hora & Ventilação Natural \\
\hline
\end{tabular}

\section{Resultados e discussões}

Avaliação do desempenho térmico de acordo com o método de simulação da NBR 15.575-1:2013

A análise do desempenho térmico do edifício através da adoção dos parâmetros do Método de simulação da NBR 15.575 (ABNT, 2013) classificou o Proj2 com níveis Mínimo e Intermediário para o período de inverno nas ZBs 4 e 2, respectivamente. Estas classificações estão de acordo com o exigido pelo Manual do Proinfância. Entretanto, nas ZBs 1, 3 e 5, a pré-escola não alcançou o nível de desempenho Mínimo. Nas ZBs 6, 7 e 8, a NBR 15.575 não exige avaliação de desempenho térmico para o período de inverno.

Já em situação de verão, as classificações de desempenho térmico variaram de nível Intermediário a Superior, dependendo da ZB. Como o Manual do Proinfância exige ao menos o nível Intermediário de desempenho térmico, a pré-escola alcançou a classificação exigida em todas as ZBs (Quadro 3). Entretanto, mesmo alcançando a classificação exigida pelo Manual, ambientes de permanência prolongada da pré-escola apresentaram temperaturas internas acima de $30^{\circ} \mathrm{C}$, como nas ZBs 6,7 e 8 . Em Teresina, cidade representativa da ZB 7, por exemplo, temperaturas internas da ordem de $33^{\circ} \mathrm{C}$ foram classificadas como desempenho térmico de nível Superior.

Quadro 3 - Classificações de desempenho térmico - parâmetros NBR 15.575-1:2013

\begin{tabular}{|c|c|c|c|c|c|c|c|c|c|}
\hline & ZB 1 & ZB 2 & ZB 3 & ZB 4 & ZB 5 & ZB 6 & ZB 7 & ZB 8 \\
\hline \multirow{2}{*}{$\begin{array}{c}\text { Classificação } \\
\text { NBR 15.575 }\end{array}$} & Inverno & $\begin{array}{c}\text { Não } \\
\text { atende }\end{array}$ & I & $\begin{array}{c}\text { Não } \\
\text { atende }\end{array}$ & M & $\begin{array}{c}\text { Não } \\
\text { atende }\end{array}$ & $\begin{array}{c}\text { Não se } \\
\text { aplica }\end{array}$ & $\begin{array}{c}\text { Não se } \\
\text { aplica }\end{array}$ & $\begin{array}{c}\text { Não se } \\
\text { aplica }\end{array}$ \\
\cline { 2 - 10 } & Verão & I & S & I & I & I & S & S & I \\
\hline
\end{tabular}

Nota: Critérios: Mínimo (M), Intermediário (I) e Superior (S). Fonte: os autores. 
Avaliação do desempenho térmico com adaptações ao método de simulação da NBR 15.575-1:2013

Em relação a avaliação anterior, a avaliação do desempenho térmico com as adaptações encontrou diferentes classificações de níveis de desempenho para a pré-escola em quase todas as ZBs em situações de inverno e verão. Houve melhora nas classificações de inverno, já que a escola passou a alcançar desempenho térmico Mínimo nas ZBs em que anteriormente não alcançava (ZBs 1, 3 e 5). Nas ZBs 2 e 4, a pré-escola manteve a mesma classificação em situação de inverno. Em situação de verão, por outro lado, houve uma piora na classificação de desempenho térmico, já que ZBs classificadas anteriormente como Nível Superior e Intermediário passaram a ser classificadas como níveis Intermediário e Mínimo, respectivamente, sendo que algumas ZBs não alcançaram a classificação mínima (Quadro 4). Dessa maneira, as classificações verificadas em situação de inverno estão de acordo com o exigido pelo Manual do Proinfância. Entretanto, apenas a ZB 2 alcança o nível de desempenho térmico Intermediário, exigido pelo Manual em situação de verão.

A melhora das classificações de desempenho térmico no inverno e a piora das classificações no verão podem se justificar, por um lado, pela utilização das cargas térmicas internas de ocupação, iluminação e equipamentos elétricos, que não haviam sido levadas em consideração na avaliação anterior. Por outro lado, o fato de as temperaturas externas de referência não serem aferidas durante a madrugada também pode ajudar a melhorar a classificação no inverno. É possível que este parâmetro tenha influenciado na classificação da pré-escola em algumas ZBs, pois as temperaturas mais baixas, de modo geral, ocorrem de madrugada, ou seja, fora do horário de ocupação da pré-escola. Novamente, os ambientes de permanência prolongada do Proj2 atingiram temperaturas que não estão de acordo com as faixas operativas de conforto, mas mesmo assim obtiveram classificações aceitas pelo Manual do Proinfância. Como exemplo, alguns ambientes da pré-escola apresentaram temperaturas da ordem de $6^{\circ} \mathrm{C}$ na ZB 1, sendo classificada com nível de desempenho térmico Mínimo e, portanto, aceito pelo Manual do Programa.

\begin{tabular}{|c|c|c|c|c|c|c|c|c|c|}
\hline & & ZB 1 & ZB 2 & ZB 3 & ZB 4 & ZB 5 & ZB 6 & ZB 7 & ZB 8 \\
\hline \multirow{2}{*}{$\begin{array}{l}\text { Classificação } \\
\text { NBR } 15.575\end{array}$} & Inverno & $M$ & 1 & $M$ & $M$ & $M$ & $\begin{array}{c}\text { Não se } \\
\text { aplica }\end{array}$ & $\begin{array}{c}\text { Não se } \\
\text { aplica }\end{array}$ & $\begin{array}{c}\text { Não se } \\
\text { aplica }\end{array}$ \\
\hline & Verão & $\begin{array}{c}\text { Não } \\
\text { atende }\end{array}$ & 1 & $M$ & $\begin{array}{c}\text { Não } \\
\text { atende }\end{array}$ & $\begin{array}{l}\text { Não } \\
\text { atende }\end{array}$ & $M$ & $M$ & $\begin{array}{c}\text { Não } \\
\text { atende }\end{array}$ \\
\hline
\end{tabular}

Nota: Critérios: Mínimo (M), Intermediário (I) e Superior (S). Fonte: os autores.

\section{Resultados de conforto térmico}

A análise do conforto térmico pelo Modelo Adaptativo mostrou que as ZBs 1, 2 e 3 apresentaram mais horas com temperaturas fora da zona de conforto devido ao frio e as ZBs 7 e 8 devido ao calor, conforme esperado. Nas ZBs 1, 2 e 3, o conforto térmico foi alcançado para menos de $50 \%$ do período de ocupação da escola durante os meses de inverno. Por outro lado, quase todos os ambientes de permanência prolongada dessas mesmas ZBs alcançaram temperaturas de conforto térmico em mais de $80 \%$ das horas de ocupação durante o período de verão. Os resultados indicam que o Proj2 atende melhor às condições de conforto no verão. Os POCs das ZBs 6, 7 e 8 no período de verão, apresentaram resultados melhores do que os POCs verificados para inverno nas ZBs 1,2 e 3. Dessa maneira, o Proj2 demonstra ser mais adequado para as zonas bioclimáticas mais quentes. A Figura 4 apresenta a média anual do POC da pré-escola por ZB. O valor 
representa a média dos POCs anuais de cada ambiente de permanência prolongada, ponderada pela respectiva área.

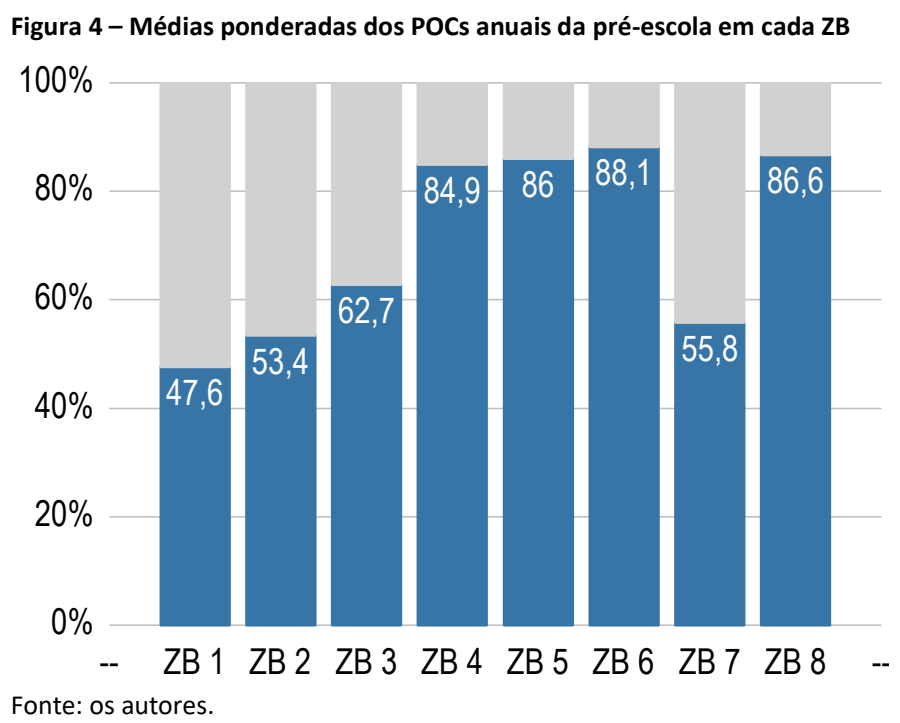

A Figura 5 mostra a média de POC da pré-escola por ZB no inverno e no verão. O valor representa a média dos POCs de cada ambiente de permanência prolongada, ponderada pela respectiva área, nos meses de inverno (junho, julho e agosto) e nos meses de verão (novembro, dezembro e fevereiro). Como para as ZBs 6, 7 e 8 não é exigida a avaliação térmica para inverno, o gráfico de inverno apresenta os resultados da ZB 1 à ZB 5 .

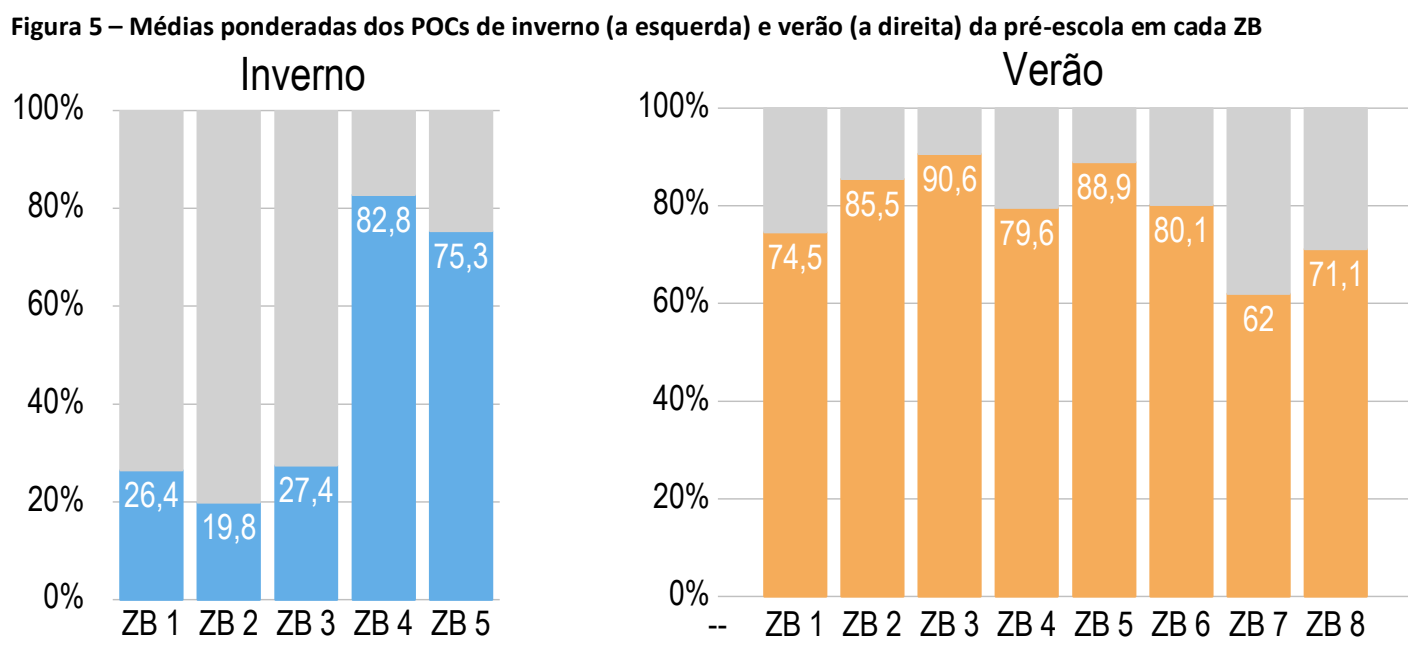

Fonte: os autores.

Para comparar duas ZBs bem distintas, a Figura 6 abaixo apresenta as temperaturas encontradas em um dos ambientes de permanência prolongada (Creche 1 ) durante todo o ano nas ZBs 1 e 7 e uma faixa de temperaturas mínimas e máximas operativas de conforto calculada. Na ZB 1, podemos verificar a predominância de temperaturas operativas fora da faixa de conforto, majoritariamente, em situações de frio, se acentuando no período de inverno. Por outro lado, na ZB 7, podemos notar desconforto em relação ao calor durante todos os meses do ano e que não há temperaturas de desconforto em relação ao frio nesta ZB. 


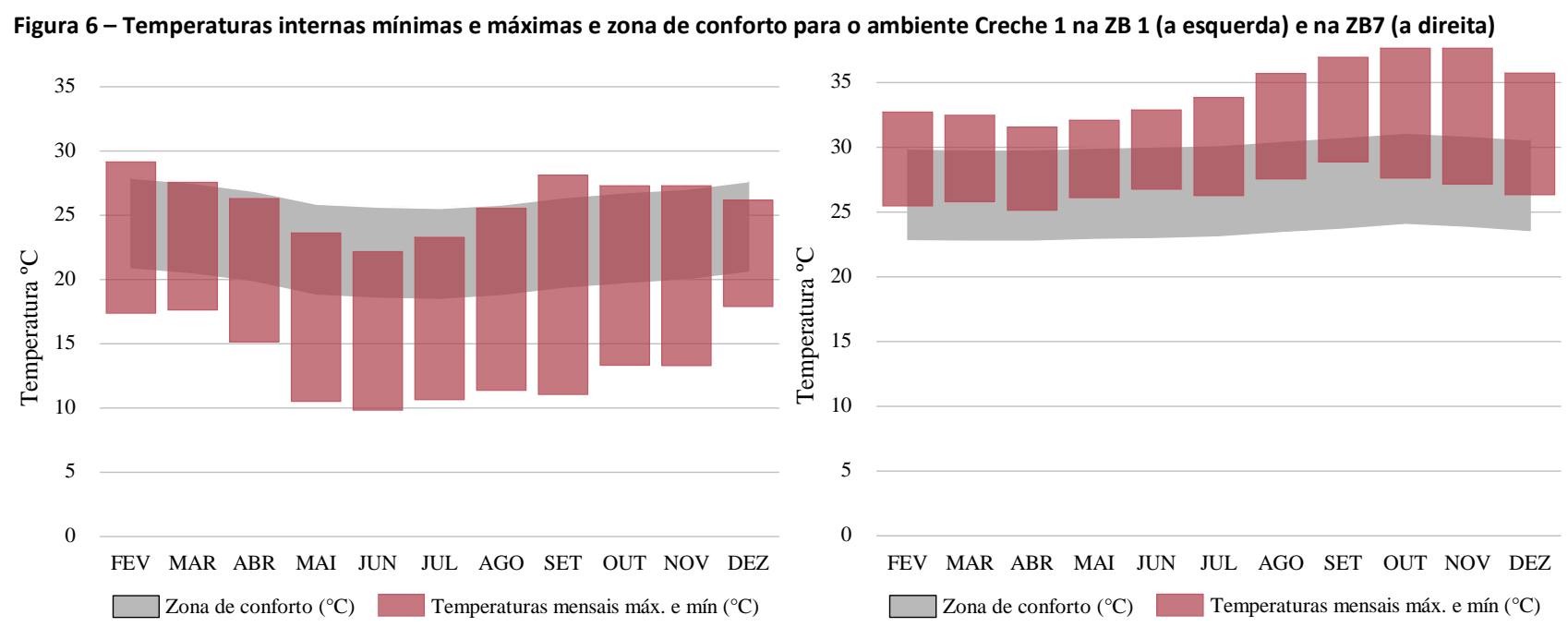

A compilação dos resultados obtidos conforme os métodos das duas normativas sugere um comparativo entre as mesmas e críticas quanto ao método de simulação da NBR 15.575-1. É evidente que os parâmetros de avaliação de desempenho térmico e de análise de conforto térmico são diferentes. O Modelo Adaptativo da Standard 55 avalia o conforto térmico para os usuários, enquanto a NBR 15.575 avalia o desempenho térmico do edifício. No entanto, a NBR 15.575 é a única referência brasileira para avaliar as temperaturas internas resultantes para as pré-escolas do Proinfância, sendo indicado pelo próprio Manual de orientações técnicas do Proinfância. Os parâmetros da Standard 55 consideram cargas internas de ocupação, iluminação artificial e equipamentos, além de permitir os efeitos de zonas naturalmente ventiladas e levar em conta as variações climáticas anuais. Por outro lado, a NBR 15.575-1 considera apenas influências climáticas externas, não utiliza as cargas térmicas internas, não apresenta exigências quanto às trocas térmicas da edificação com o solo, indica o uso de ventilação natural simplificada através de renovações de ar por hora, além de analisar somente os dias típicos de verão e inverno. Desta forma, espera-se que as temperaturas resultantes da análise de conforto térmico sejam mais realistas do que aquelas obtidas a partir da análise do desempenho térmico.

A avaliação de conforto térmico e a avaliação do desempenho térmico sem as adaptações mostraram que o Proj2 é mais adequado para zonas bioclimáticas mais quentes, quando os níveis de desempenho térmico alcançados são melhores e os períodos de desconforto são menores. Entretanto, o desempenho térmico aferido pela NBR 15.575-1 não significa conforto térmico, já que temperaturas resultantes internas da ordem de $6,26^{\circ} \mathrm{C}$ verificada em Curitiba ou $33,76^{\circ} \mathrm{C}$ verificada em Teresina, não podem representar conforto térmico, ainda que mínimo. Os resultados de desempenho térmico não podem ser tomados como parâmetros de qualidade para um edifício ocupado por crianças menores de seis anos e durante atividades educacionais.

\section{Adaptações adotadas para o método de simulação da NBR 15.575}

Além da classificação não possuir critérios muito exigentes, os resultados obtidos através do método de simulação da NBR 15.575-1 levantam algumas dúvidas. O método de simulação não exige certos parâmetros importantes na modelagem, capazes de alterar os resultados de classificação. Se determinados parâmetros não são considerados pelo método da norma a ponto de serem negligenciados, estes não 
deveriam causar modificações nas classificações. Comparando os resultados das classificações de desempenho térmico obtidas de acordo com o Método de simulação da NBR 15.575 sem adaptações e com adaptações, podemos perceber que eles se alteram em quase todas as situações. Apenas em duas situações (ZB 2 - inverno e ZB 4 - inverno) as classificações obtidas foram as mesmas. Os resultados de desempenho térmico possuem classificações melhores para verão na avaliação de desempenho sem adaptações, e para inverno na avaliação com adaptações. Com isso, podemos afirmar que há um aumento das temperaturas internas com a aplicação dos parâmetros não utilizados pela NBR, possivelmente em relação a utilização das cargas térmicas internas e trocas térmicas entre piso e solo. Além disso, a utilização das temperaturas externas de referência e temperaturas internas somente no horário de ocupação da pré-escola, pode afetar a classificação para o período de inverno, visto que não são utilizadas as temperaturas da madrugada que em geral são as mais frias. Consequentemente a aplicação dos parâmetros impacta nos resultados da avaliação de desempenho térmico.

Para um aperfeiçoamento do Método de simulação da NBR 15.575:2013, o Quadro 5 apresenta as adaptações adotadas neste estudo, que são recomendações para a avaliação térmica apresentada pelo Manual do Proinfância.

Quadro 5 - Avaliação de desempenho térmico segundo a NBR 15.575 - Limitações e recomendações
\begin{tabular}{|c|c|}
\hline $\begin{array}{c}\text { Desempenho térmico } \\
\text { Método de simulação - ABNT NBR 15.575-1 } \\
\text { Limitações }\end{array}$ & $\begin{array}{c}\text { Desempenho térmico } \\
\text { Método de simulação - ABNT NBR 15.575-1 } \\
\text { Recomendações }\end{array}$ \\
\hline $\begin{array}{c}\text { Não diferencia temperaturas resultantes das horas } \\
\text { ocupadas e não ocupadas. }\end{array}$ & $\begin{array}{c}\text { Quando for utilizada para diferentes tipologias, } \\
\text { considerar apenas horas ocupadas da edificação. }\end{array}$ \\
\hline $\begin{array}{c}\text { Não leva em conta trocas térmicas do piso com o } \\
\text { solo. }\end{array}$ & $\begin{array}{c}\text { Quando a edificação avaliada tiver os ambientes de } \\
\text { permanência prolongada em contato com o solo, } \\
\text { devem ser levadas em conta as temperaturas do } \\
\text { solo diretamente abaixo do piso da edificação. }\end{array}$ \\
\hline $\begin{array}{c}\text { Não considera cargas térmicas internas } \\
\text { provenientes de pessoas, iluminação e } \\
\text { equipamentos elétricos. }\end{array}$ & $\begin{array}{c}\text { Consideração das cargas térmicas internas, devido a } \\
\text { influência destas na temperatura interna. }\end{array}$ \\
\hline
\end{tabular}

Fonte: os autores.

\section{Recomendações de alterações para o Manual}

A falta de uma normativa nacional para edificações escolares sugere que haja uma atenção na elaboração de manuais que tragam recomendações para o desenvolvimento de projetos para escolas e pré-escolas. O RTQ-C possui um método de avaliação do conforto térmico para edifícios não climatizados através da simulação e quantificação do percentual de horas ocupadas em conforto (POC), similar ao que foi usado no método deste estudo. Como este regulamento contempla edificações comerciais e públicas como escolas, por exemplo, poderia ser considerado como de cumprimento obrigatório para a avaliação das pré-escolas do Programa Proinfância no lugar da NBR 15.575-1. O RTQ-C indica a utilização de um método de avaliação de conforto reconhecido, como os apresentados na ASHRAE Standard 55 ou na ISO 7730 . O regulamento exige que ambientes não climatizados sejam simulados por softwares de avaliação termoenergética reconhecidos e que seja calculado o POC dos ambientes de permanência prolongada. Estes percentuais são classificados conforme o regulamento para, após isso, ser possível calcular o nível de eficiência energética (INMETRO, 2013).

Para que os projetos padrão do Proinfância alcancem níveis de desempenho e conforto térmico adequados ao desenvolvimento das atividades escolares, é necessária uma adequação das exigências estabelecidas atualmente. A seguir, estão apresentadas algumas recomendações visando o melhoramento das condições térmicas para a ocupação dos usuários (Quadro 6). 
Quadro 6- Recomendações para desempenho e conforto térmico

Recomendações para alcançar níveis de desempenho e conforto térmico adequados nos projetos do Programa Proinfância

1. Alterações no Manual de diretrizes técnicas para projetar edifícios educacionais do Programa Proinfância: adaptações dos critérios de simulação da NBR 15.575 para edificações escolares.

2. Alterações do Manual de diretrizes técnicas para projetar edifícios educacionais do Programa Proinfância: exigência de níveis mais elevados de desempenho térmico da NBR 15.575. Exemplo: desempenho Superior para inverno e verão em todas as zonas bioclimáticas pertinentes

3. Exigência do cumprimento obrigatório do método de simulação do RTQ-C para comprovação do conforto térmico em edificações não climatizadas

4. Desenvolvimento de normativa nacional para avaliação de conforto térmico em edificações escolares Fonte: os autores.

\section{Conclusão}

Este trabalho avaliou o método de avaliação térmica das pré-escolas apresentado pelo Manual de orientações técnicas do Programa Proinfância estabelecendo uma discussão sobre o modo como é feita a avaliação térmica dos projetos padrão do Programa.

Verificou-se que o Manual do Programa não possui exigências quanto ao conforto térmico dos usuários das pré-escolas. Foram encontrados resultados de desempenho térmico de temperaturas resultantes nos ambientes de permanência prolongada aceitos para a classificação exigida pelo Manual. Entretanto, muitas destas temperaturas resultantes quando correlacionadas a temperaturas operativas de conforto térmico, se encontram fora da zona de conforto calculada para $80 \%$ dos usuários satisfeitos. Portanto, o nível de desempenho térmico exigido pelo Manual para os projetos das pré-escolas não está relacionado ao nível adequado de conforto térmico dos usuários.

A avaliação térmica possui algumas incertezas devido a alguns parâmetros não definidos no método de simulação da NBR 15.575:2013. Soma-se a isso o fato de que a norma foi desenvolvida para a avaliação de edificações habitacionais, e não educacionais. O Manual do Proinfância também não deixa claro alguns parâmetros para a realização da avaliação térmica das pré-escolas. Sendo assim, foram realizadas simulações de acordo com o Método de simulação da NBR e outras simulações com adaptações ao mesmo Método. Com isso, pôde ser verificado que os parâmetros utilizados nas simulações com adaptações possuem influência na avaliação de desempenho, podendo modificar os níveis de classificação de desempenho térmico do Proj2. Para futuras pesquisas e resultados mais congruentes da sensibilidade de cada um dos parâmetros adotados como adaptações neste estudo, poderiam ser realizadas simulações avaliando o impacto de cada um dos parâmetros separadamente. A utilização de uma normativa elaborada para habitações para a avaliação de edifícios educacionais exige, no mínimo, que sejam desenvolvidas adaptações para que os níveis de classificações de desempenho térmico da mesma normativa possam ser utilizados.

Os resultados alcançados pelas simulações computacionais são indicativos adequados de comportamento térmico, podendo ser aceitos para definir recomendações para a avaliação térmica das pré-escolas, e exigir níveis adequados de conforto térmico necessários às atividades escolares. Porém, futuros trabalhos podem realizar medições térmicas in loco e avaliar o conforto térmico pós-ocupação das pré-escolas, complementando resultados de simulações computacionais.

Torna-se evidente a importância do desenvolvimento de normativa específica para avaliação de conforto térmico em tipologias escolares, ou no caso do Programa Proinfância, que o Manual apresente parâmetros de avaliação térmica mais definidos. 


\section{Referências}

ABNT - ASSOCIAÇÃO BRASILEIRA DE NORMAS TÉCNICAS. NBR 15.220-2: Desempenho Térmico de Edificações Parte 2: Métodos de cálculo da transmitância térmica, da capacidade térmica, do atraso térmico e do fator solar de elementos e componentes de edificações. Rio de Janeiro: ABNT, $2005 a$.

ABNT - ASSOCIAÇÃO BRASILEIRA DE NORMAS TÉCNICAS. NBR 15.220-3: Desempenho Térmico de Edificações Parte 3: Zoneamento bioclimático brasileiro e diretrizes construtivas para habitações de unifamiliares de interesse social. Rio de Janeiro: ABNT, 2005b.

ABNT - ASSOCIAÇÃO BRASILEIRA DE NORMAS TÉCNICAS. NBR 15.575-1: Edificações Habitacionais - Desempenho parte 1: Requisitos Gerais. Rio de Janeiro: ABNT, 2013.

ASHRAE - AMERICAN SOCIETY OF HEATING, REFRIGERATING AND AIR CONDITIONING ENGINEERS. ANSI/ASHRAE 55: Thermal environmental conditions for human occupancy. Atlanta, 2017.

BABICK, C. S.; TORRES, M. C. A. Análise do desempenho térmico, lumínico e de ventilação natural de projeto padrão de edifício escolar do FNDE de acordo com os requisitos de normas e referenciais nacionais e internacionais nas 8 zonas bioclimáticas brasileiras. Revista de Engenharia Civil IMED, Passo Fundo, 2017, v. 4, n. 2, p. 110-128. DOI: https://doi.org/10.18256/2358-6508.2017.v4i2.2283.

BRASIL. Ministério da Educação. Fundo Nacional para o Desenvolvimento da Educação (FNDE), Ministério da Educação. Relatório Situação Creches por Tipologia. Planilha fornecida aos autores pela CODIN/FNDE em 01 nov. 2018.

BRASIL. Ministério da Educação. Fundo Nacional para o Desenvolvimento da Educação (FNDE), Ministério da Educação. Projetos Arquitetônicos para construção. Disponível em:

http://www.fnde.gov.br/programas/proinfancia. Acesso em: 28/02/2018

BRASIL. Ministério da Educação. Memorial Descritivo. Projeto Proinfância Tipo 2. Fundo Nacional de Desenvolvimento da Educação - FNDE. Brasília, 2013. Disponível em: http://www.fnde.gov.br/programas/proinfancia/areas-para-gestores/manuais. Acesso em: 28/02/2018.

BRASIL. Ministério da Educação. Manual de Orientações Técnicas. Volume 2. Elaboração de Projetos de Edificações Escolares: Educação Infantil. Disponível em: http://www.fnde.gov.br/programas/proinfancia/areas-paragestores/manuais. Acesso em: 28/02/2018.

INMETRO - INSTITUTO NACIONAL DE METROLOGIA, NORMALIZAÇÃO E QUALIDADE INDUSTRIAL. Regulamento Técnico da Qualidade do Nível de Eficiência Energética para Edificações Comerciais, de Serviço e Públicas (RTQ-C). Publicado através da portaria $\mathrm{n}^{\circ} 372$, de 17 de setembro de 2010. Com alterações das portarias: $\mathrm{n}^{\circ} 17$ de 2012 e $\mathrm{n}^{\circ} 299$ de 2013. Disponível em:

http://pbeedifica.com.br/sites/default/files/projetos/etiquetagem/comercial/downloads/Port3722010_RTQ_Def_Edificacoes-C_rev01.pdf. Acesso em: 20/02/2018.

KOWALTOWSKI, Doris C. C. K.; Arquitetura escolar: o projeto do ambiente de ensino. São Paulo: Oficina de Textos, 2011.

MODLER, N.L.; BERLEZE, A.S.; TSUTSUMI, E.K.; LINCZUK, V.C.C.; AZEVEDO, G.A.N. Avaliação de desempenho de um padrão do programa Proinfância: escola de educação infantil no sul do Brasil. Gestão e Tecnologia de Projetos, São Carlos, 2018, v. 13, n. 2, p. 95-118. DOI: http://dx.doi.org/10.11606/gtp.v13i2.126495.

ORDENES, M.; PEDRINI, A.; GHISI, E.; LAMBERTS, R. Metodologia utilizada na elaboração da biblioteca de materiais e componentes construtivos brasileiros para simulações no visualdoe-3.1. Laboratório de Eficiência Energética em Edificações, Núcleo de Pesquisa em Construção, Departamento de Engenharia Civil. Universidade Federal de Santa Catarina, Florianópolis, 2003. 
PEGLOW, J.; RITTER, V.; RONCA, A.; PEREIRA, R.; CUNHA, E.; RHEINGANTZ, P. Avaliação do conforto térmico de escola municipal de educação infantil em Pelotas/RS - ZB2. In: ENCONTRO NACIONAL DE TECNOLOGIA DO AMBIENTE CONSTRUÍDO, 16, 2016, São Paulo. Anais [...]. Porto Alegre: ANTAC, 2016.

RHEINGANTZ, P.; CUNHA, E. G.; PEGLOW, J. S.; RITTER, V.; QUINTANA L. C.; MACIEL T. S.; BELTRAME C.; DUARTE C. M.; SILVA A. C. B. Place, architecture, design and thermal comfort: a municipal day care childhood centre in colônia C3, Pelotas/RS, Brazil. Journal of Civil Engineering and Architecture. 2017. p. 364-379. DOI: http://10.17265/19347359/2017.04.006

SILVA, A. S.; SORGATO, M. J.; MAZZAFERRO, L.; MELO, A. P.; GHISI, E. Incerteza do método de simulação da NBR 15.575-1 para a avaliação do desempenho térmico de habitações. Ambiente Construído, Porto Alegre, 2014, v. 14, n. 4, p. 103-117. DOI: https://doi.org/10.1590/S1678-86212014000400008

SOARES, M. M.; SILVA, A. C. S. B. da. Análise e compatibilização dos métodos simplificado e por simulação da NBR 15.575: zona bioclimática 2. Ambiente Construído, Porto Alegre, 2017, v. 17, n. 1, p. 305-327. DOI: http://dx.doi.org/10.1590/s1678-86212017000100137

SORGATO, M. J.; MELO, A. P.; MARINOSKI, D. L.; LAMBERTS, R. Análise do procedimento de simulação da NBR 15.575 para avaliação do desempenho térmico de edificações residenciais. Ambiente Construído, Porto Alegre, 2014, v. 14, n. 4, p. 83-101. DOI: https://doi.org/10.1590/S1678-86212014000400007

\section{Gabriela Sartori}

Arquiteta e Urbanista. Mestre em Engenharia Civil pela Universidade Federal do Rio Grande do Sul. Doutoranda do Programa de Pós-Graduação em Engenharia Civil: Construção e Infraestrutura da Universidade Federal do Rio Grande do Sul. Endereço postal: Avenida Osvaldo Aranha, 99, $7^{\circ}$ andar. Porto Alegre, Rio Grande do Sul - Brasil. CEP 90035-190.

\section{Luiz Carlos Pinto da Silva Filho}

Engenheiro Civil. Doutor em Engenharia Civil pela Universidade de Leeds. Professor titular da Escola de Engenharia, professor permanente do Programa de Pós-Graduação em Engenharia Civil: Construção e Infraestrutura da Universidade Federal do Rio Grande do Sul. Endereço postal: Avenida Osvaldo Aranha, 99, $7^{\circ}$ andar. Porto Alegre, Rio Grande do Sul - Brasil. CEP 90035-190.

\section{Maurício Carvalho Ayres Torres}

Arquiteto e Urbanista. Doutor em Engenharia Civil pela Universidade Politécnica da Catalunha. Professor adjunto da Faculdade de Arquitetura, professor convidado do Programa de Pós-Graduação em Engenharia Civil: Construção e Infraestrutura da Universidade Federal do Rio Grande do Sul. Endereço postal: Avenida Osvaldo Aranha, 99, $7^{\circ}$ andar. Porto Alegre, Rio Grande do Sul - Brasil. CEP 90035-190. 